\title{
Research of Control Strategy on DC Side of Hybrid Energy Storage in Micro Grid
}

\author{
Tieyan Zhangi ${ }^{1,}{ }^{3}$, Di Bai ${ }^{1,2}$, Zheng Yang ${ }^{2}$, Zhibin Long $^{4}$ and Baiyu Gao \\ ${ }^{1}$ College of Information \& Electrical Engineering, Shenyang Agricultural \\ University, Shenyang 110866, China \\ ${ }^{2}$ Shenyang Institute of Engineering, Shenyang 110136, China \\ ${ }^{3}$ Shenyang University of Technology, Shenyang 110870, China \\ ${ }^{4}$ The University of New South Wales, Sydney, 2052, Australia \\ ${ }^{5}$ Department of Marketing, State Grid Liaoning Electric Power Supply Co. Ltd., \\ Shenyang 110000, China \\ *Corresponding author: zty@sie.edu.cn

\begin{abstract}
The uncertainty and fluctuation brought by distributed type of intermittent power generation in micro grid bring huge challenges to power quality of miero grid in isolating operation and power control in parallel operation. Nevertheles energy storage is able to well solve this problem. Hybrid energy storage integrates the respective advantages of storage battery and supercapacitor to have improved the performance of energy storage system. Service life of storage battery is tightly related to its charging/discharging times and problem of frequent charging/discharging storage battery still exists in current hybrid energy storage technology. In this paper, in respectively puts forward control strategies for storage battery and supercapaciton As to control strategy for storage battery, it uses double-layered control strategy, namely, single loop control and power hysteresis control, to feedback low-frequency fluctuation of power and reduce charging/discharging frequency of storage battery. As to control strategy for supercapacitor, it usesinner loop current with power to control voltage in outer loop so as to feedback high-frequency fluctuation of power and it is able to well maintain stability of DC bus voltage. Simulation results suggest the validity of aforesaid control strategies.
\end{abstract}

Keyword Micro Gid. Hybrid Energy Storage; Supercapacitor; Storage Battery; Power Feedforward

\section{Introduction}

Global shortage of resources makes micro grid gradually become the hot topic worldwide and energy storage is regarded as the key element for stable operation in micro grid. Researches at different levels have been made both at home and abroad on control srategies related to energy storage capacity, energy storage method and energy storage charging/discharging.

In Reference [1], it uses storage battery as energy storage in micro gird and it designs a double-layered control strategy, namely storage battery voltage control in outer loop and current control in inner loop, to stabilize voltage in micro grid DC bus. Nevertheless the single energy storage method is unable to meet with micro grid's demand for stability. In Reference [2], it establishes the hybrid energy storage by using storage battery and supercapacitor. It puts forward the hybrid energy storage control strategy to display the advantage of hybrid energy storage. Nevertheless it fails to take battery status into consideration and it might influence the service life of battery. In Reference [3], it uses double0-layered control strategy to enhance its judgment over state of charges in batteries 
and calculates equivalent service life of batteries to keep batteries from being damaged caused by extra charging/discharging. In this paper, in order to further improve micro grid DC bus voltage stability, it puts forward the control strategy containing power feeforward. Besides, with the consideration of the tight relationship between storage battery's charging/discharging times and its service life and the theory that supercapacitor has infinite charging/discharging capacity, it designs a control strategy to further reduce charging/discharging times of storage batteries so as to extend the service life of storage batteries.

\section{Hybrid Energy Storage System Structure}

Hybrid energy storage system composed of storage battery and super capacitator is divided into three categories in its front-stage structure, namely, direct parallel structure, single DC/DC parallel structure and double DC/DC parallel structure [4]. In this paper, it, uses double DC/DC parallel structure, in which storage battery and supercapacitor for $\mathrm{m}$ parallel connection respectively by power controller and DC bus [5]. Charging/discharging powers of battery and supercapacitor are respectiyely and independently controlled by two controllers to meet with the charging/discharging system's demand for actively responding to external system hrough precise control. In back-stage structure, it uses the two-way DC/AC convertor to connect energy storage system and micro grid $\mathrm{AC}$ bus as illustrated in the ollowing figute:

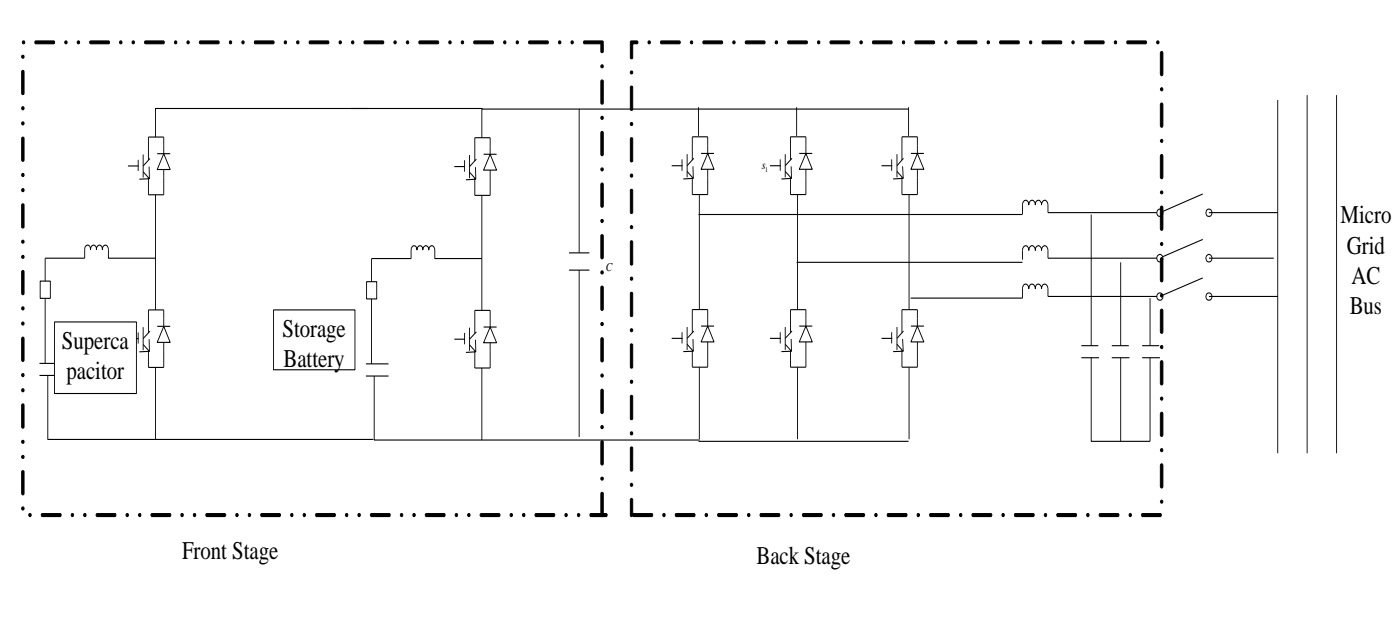

\section{Figure 1. Hybrid Energy Storage Structure}

In its front-stage structure, it uses the two-way DC-DC convertor. It uses the doubleway DC-DCConvertor to store the extra energy existing in supply load in energy storage system in the micro grid and it uses the double-way DC-DC inverter to transmit energy stored in energy storage system to DC bus when DC bus voltage is low to meet with the oad demand [6]. Its back-stage structure belongs to the DC-AC inverter rectifier and it is composed of the classic three-phase full-bridge circuit and LC filter and it is able to realize DC/AC switching and double-way power flow. Half-bridge double-way DC-DC convertor uses the complementary PWM control method and its back-stage DC-AC inverter rectifier uses the classic SVPWM method. 


\section{DC/DC Converter's Mathematical Model}

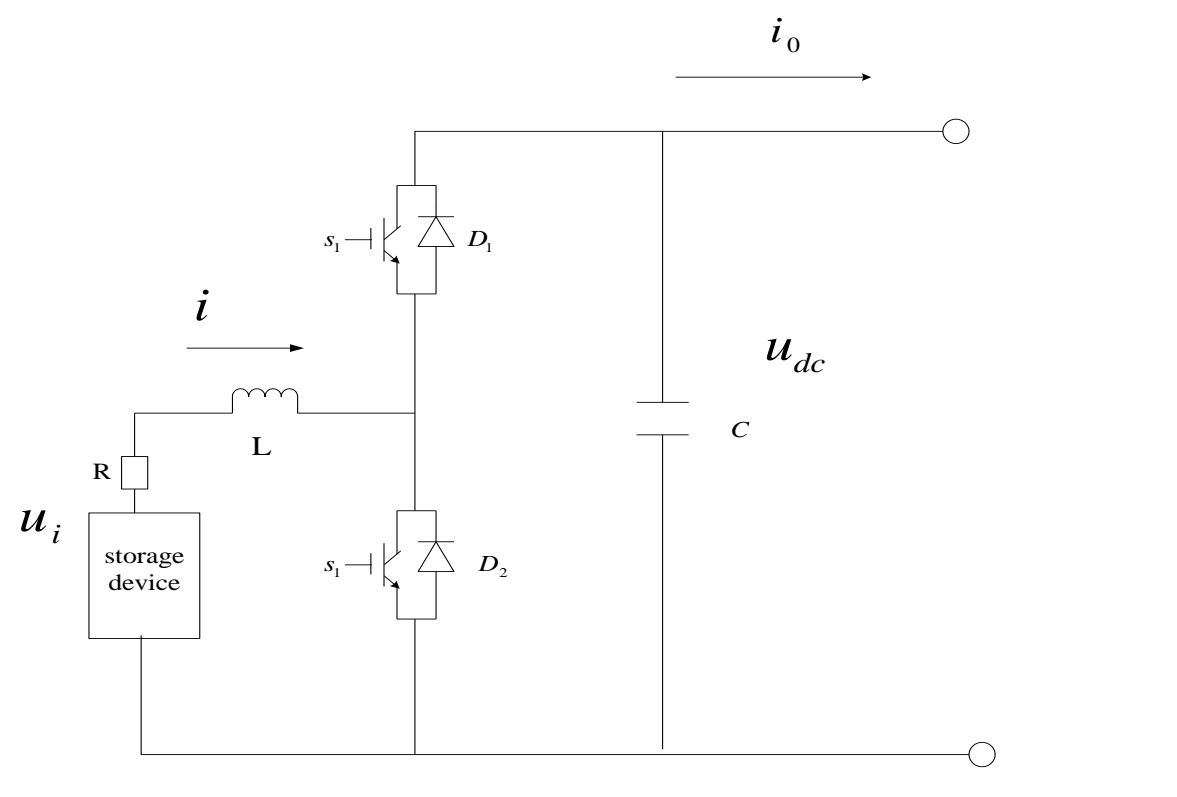

Figure 2. DC/DC Power Convertor Structuré

Control basis on DC side uses the double-way DC/DC Circuit's current loop control [7], and as the charging/discharging controller, it is able to transmit energy. Firstly, let's analyze the double-way half-bridge Converter's mathematical model. As what is illustrated in Figure 2, it is the double-way hal bridge converter's circuit structure. Up tubes and down tuples form compementary conduction. Up tube is open in high level and when switches are on the average, then

$\mathrm{C} \frac{\mathrm{du} \mathrm{dc}_{\mathrm{d}}}{\mathrm{dt}}=\mathrm{d} \cdot \mathrm{i}-\mathrm{i}_{\mathrm{g}}$

Error! Reference source not found.

$\mathrm{d}$ is Duty Radio. With the consideration that double power frequency fluctuation exists in system output, it uses supercapacitor to compensate for active wave power. Therefore supercapacitor contains double frequency AC component. In the equation,

$\mathrm{i}=\mathrm{i}_{\mathrm{o}}+\mathrm{i}_{\mathrm{t}} \cos (2 \omega \mathrm{t})+\mathrm{i}_{\mathrm{s}} \sin (2 \omega \mathrm{t})$

$d=d_{o}+d_{t} \cos (2 \omega t)+d_{s} \sin (2 \omega t)$

In roduce (3) and (4) to (1), we can reach:

$\left\{\begin{array}{c}\mathrm{L} \frac{\mathrm{di}_{\mathrm{o}}}{\mathrm{dt}}+\mathrm{Ri}_{\mathrm{o}}=\mathrm{u}_{\mathrm{i}}-\mathrm{d} \cdot \mathrm{u}_{\mathrm{dc}} \\ \mathrm{L}\left(\frac{\mathrm{di}_{\mathrm{t}}}{\mathrm{dt}}+2 \omega \mathrm{i}_{\mathrm{s}}\right)+\mathrm{Ri}_{\mathrm{t}}=-\mathrm{d}_{\mathrm{t}} \cdot \mathrm{u}_{\mathrm{dc}} \\ \mathrm{L}\left(\frac{\mathrm{di} \mathrm{i}_{\mathrm{s}}}{\mathrm{dt}}+2 \omega \mathrm{i}_{\mathrm{t}}\right)+\mathrm{Ri}_{\mathrm{s}}=-\mathrm{d}_{\mathrm{s}} \cdot \mathrm{u}_{\mathrm{dc}}\end{array}\right.$

Introduce (3) and (4) to (2), we can reach:

$\left\{\begin{array}{c}\mathrm{C} \frac{\mathrm{du} d \mathrm{dc}}{\mathrm{dt}}=\mathrm{d}_{0} \mathrm{i}_{\mathrm{o}}-\mathrm{i}_{\mathrm{o}} \\ \mathrm{d}_{0} \mathrm{i}_{\mathrm{t}}+\mathrm{d}_{\mathrm{c}} \mathrm{i}_{\mathrm{o}}-\mathrm{i}_{\mathrm{ct}}=0 \\ \mathrm{~d}_{0} \mathrm{i}_{\mathrm{s}}+\mathrm{d}_{\mathrm{s}} \mathrm{i}_{\mathrm{o}}-\mathrm{i}_{\mathrm{os}}=0\end{array}\right.$ 
Linearize (5) and we can reach:

Error! Reference source not found.

Error! Reference source not found.

Linearize (6) and we can reach

$$
\begin{aligned}
& \left\{\begin{array}{c}
\mathrm{D}_{0}{ }^{(\mathrm{ss})} \mathrm{I}_{0}{ }^{(\mathrm{ss})}=\mathrm{I}_{00}{ }^{(\mathrm{ss})} \\
\mathrm{sC} \tilde{\mathrm{u}}_{\mathrm{dc}}(\mathrm{s})=\mathrm{D}_{0}{ }^{\left({ }^{(s)}\right)} \tilde{\mathrm{I}}_{\mathrm{o}}(\mathrm{s})+\mathrm{o}^{(\mathrm{ss})} \tilde{\mathrm{d}}_{0}(\mathrm{~s})-\tilde{\mathrm{r}}_{\mathrm{oo}}(\mathrm{s})
\end{array}\right.
\end{aligned}
$$

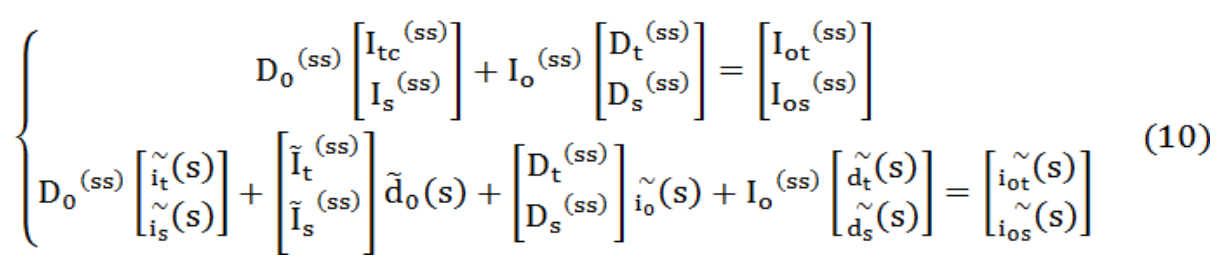

\section{Control Strategy on DC Side}

Control strategy on DC side consists of two part hamely, storage battery by-pass control strategy and supercapacitor control strategy Storage battery control strategy consists of storage battery current inner loop and current directives generation system and supercapacitor control strategy consists of capacitor current Control inner loop and DC bus voltage outer loop and the cooperation of two strategies finishes power distribution. With the consideration that service life of storage battery is tightly related to charging/discharging times and the power value is low in smooth parts in regular control strategies, it still uses storage battery to adjust charging/discharging, which leads to frequent charging/discharging of storage battery. In this paper, it improves the former strategies by calculating the difference between active power value and reference value on DC control side and AC side before making them enter LPF and hysteresis control is able to judge the value of current power. When power is lower than the given value, it directly controls work status of storage battery to stop working and supercapacitor will start charging/discharging work. When power is higher than the given value, it makes judgment over current stage of charges in the battery to confirm whether or not to use charging/discharging formaking adjustment.

\subsection{Storage Battery Control Strategy in Hybrid Energy Storage}

DC bus voltage control loop's velocity much slower than that of DC/DC current loop. Therefore we can ignore dynamic disturbance of DC bus voltage and we can directly use equation (11), to design battery current loop control as illustrated in the following figure:

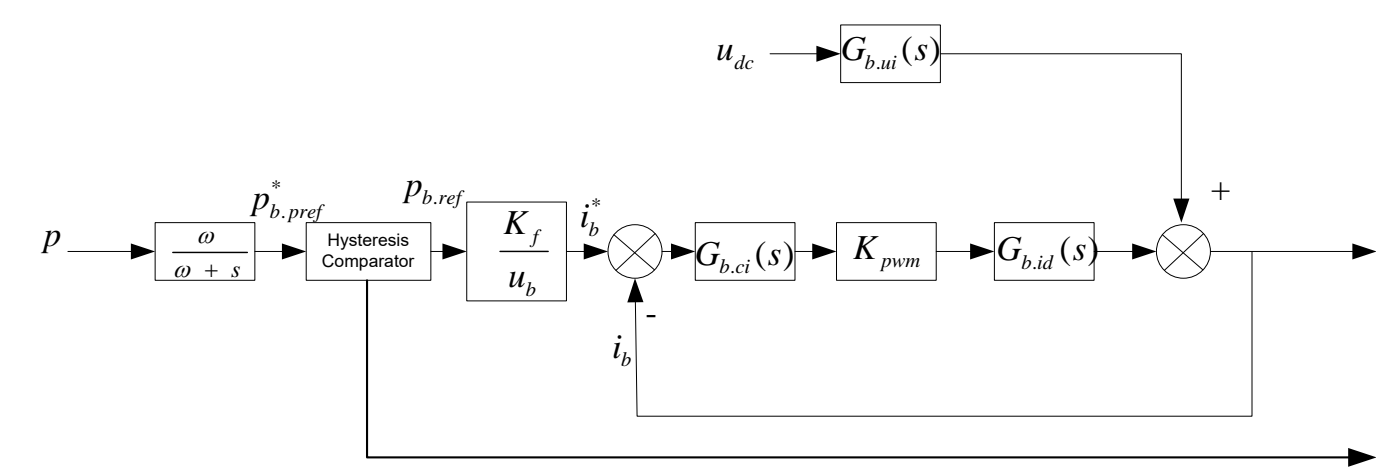

Figure 3. Storage Battery Control 
In this figure, $\mathrm{P}$ is active power on DC/AD side, Error! Reference source not found. belongs to LPF, it is power in smooth storage battery parts and it uses hysteresis comparator to control work status of storage battery, Error! Reference source not found. is transfer function for signals of low duty cycle in inductive current, Error! Reference source not found. is PI controller transfer function,Error! Reference source not found. is PWM equivalent gain valueError! Reference source not found.. The expressions are as follows:

$$
\begin{aligned}
& G_{\mathrm{b} . \mathrm{id}}(\mathrm{s})=-\frac{\mathrm{U}_{\mathrm{dc}}^{(\mathrm{ss})}}{\mathrm{sL}_{\mathrm{b}}+\mathrm{R}} \\
& \mathrm{G}_{\mathrm{b} . \mathrm{iu}}(\mathrm{s})=-\frac{\mathrm{D}_{0}^{(\mathrm{ss})}}{\mathrm{sL}_{\mathrm{b}}+\mathrm{R}}
\end{aligned}
$$

\subsection{Supercapacitor Control Strategy in Hybrid Energy Storage}

Supercapacitor has the characteristics of fast charging/discharging speed and large number of circular charging/discharging times and it plays the role as the fast adjustor in system. Supercapacitor undertakes the responsibility for high-frequency-fuctuation components in back-stage convertor's output power $\mathrm{P}$ and its cyrrent loop control realizes the control at millisecond level. It uses the indirect control method and the imbalance of powers in front/back sides in the entire system will lead to fluctuation of DC bus voltage. Therefore back-stage and front-stage power will maintain the balanced stage as long as we are able to control the stability on both ends of voltage capacitor. Storage battery uses power's PI double closed-loop control to better realize tracking system low-frequency tendency power. Therefore we are able to toake supe capacitor undertake high-frequency components as long as we are able to control DCbas voltage stability.



\section{Figure 4. Dual Loop Control of Supercapacitor with Power Feedforward}

Stability of DC bus voltage in micro grid is the key part for normal operation in micro grid In order to accelerate system response speed and reduce steady-status control, it introduces power feedforard control and its current amplitude command is as follows:

$$
\mathrm{I}_{\text {pref }}^{*}=\mathrm{K}_{\mathrm{sc.v}} \frac{\mathrm{p}_{\mathrm{sc} . \mathrm{pref}}}{\mathrm{u}_{\mathrm{dc}}}
$$

Error! Reference source not found. is power feedforward ratio value ranged from 0.9 to 0.98 . DC/DC converter output current is system feedforward quantity and it does not influence system stability. Therefore we do not need to consider its influence on the stability of the entire system and we need only analyze stability of the dual closed-loop system. Supercapacitor inner loop control part is much alike the part in storage batter 
without repetition. As to supercapacitor voltage outer loop control, we need firstly establish a mathematical model for DC bus voltage. Power balance in energy storage system in the stable status is as follows:

$$
\mathrm{p}-\mathrm{p}_{\mathrm{sc}}-\mathrm{p}_{\mathrm{b}}+\frac{\mathrm{U}_{\mathrm{dc}}^{2}}{\mathrm{R}_{\mathrm{L}}}=0
$$

With the consideration of instantaneous power in electrolytic capacitor, we can reach:

$$
\mathrm{p}-\mathrm{p}_{\mathrm{sc}}-\mathrm{p}_{\mathrm{b}}+\frac{\mathrm{U}_{\mathrm{dc}}^{2}}{\mathrm{R}_{\mathrm{L}}}-\frac{1}{2} \mathrm{C} \frac{\mathrm{du} \mathrm{dc}^{2}}{\mathrm{dt}}=0
$$

It makes instantaneous powers of DC/AC converter and DC bus switching, voltage and current of DC bus respectively reach:

$$
\begin{aligned}
& \mathrm{p}=\mathrm{p}_{\mathrm{o}}+\mathrm{p}_{\mathrm{t}} \cos (2 \omega \mathrm{t})+\mathrm{p}_{\mathrm{s}} \sin (2 \omega \mathrm{t}) \\
& \mathrm{u}_{\mathrm{dc}}=\mathrm{u}_{\mathrm{o}}+\mathrm{u}_{\mathrm{t}} \cos (2 \omega \mathrm{t})+\mathrm{u}_{\mathrm{s}} \sin (2 \omega \mathrm{t}) \\
& \mathrm{i}_{\mathrm{dc}}=\mathrm{i}_{\mathrm{o}}+\mathrm{i}_{\mathrm{t}} \cos (2 \omega \mathrm{t})+\mathrm{i}_{\mathrm{s}} \sin (2 \omega \mathrm{t})
\end{aligned}
$$

We can reach:

$$
\begin{aligned}
& \frac{1}{2} \mathrm{C} \frac{\mathrm{du} \mathrm{u}_{0}}{\mathrm{dt}}+\frac{\mathrm{u}_{0}}{\mathrm{R}_{\mathrm{L}}}=\mathrm{u}_{\mathrm{sc}} \mathrm{i}_{\text {sco }}+\frac{1}{2} \csc _{\mathrm{sc}} \mathrm{dt}\left(\mathrm{i}_{\text {sco }}^{2}+\frac{1}{2} \mathrm{i} 2 \frac{1}{2} \mathrm{i}_{\text {scs }}^{2}\right)-\mathrm{p}_{\mathrm{o}}+\mathrm{p}_{\mathrm{b}} \\
& \left\{\begin{array}{l}
c\left(\frac{d u_{t}}{d t}+2 \omega u_{s}\right)+\frac{u_{c}}{R_{t}}=u_{s c} i_{s c t}+L_{s c c}\left(c_{s s} \frac{d i_{s c o}}{d}+i_{s c o} \frac{d i_{s c t}}{d}+\omega i_{s c o} i_{s c s}\right)-p_{t} \\
c\left(\frac{d u_{s}}{d t}+2 \omega u_{t}\right) \frac{u_{s}}{R_{t}}=u_{s c} i_{s c o s}+L_{s c}\left(i_{s c s} \frac{d i_{s c o}}{d}+i_{s c o} \frac{d i_{s c t}}{d}+\omega i_{s c o} i_{s c t}\right)-p_{s}
\end{array}\right.
\end{aligned}
$$

The above equation describes the dynamic process of DC bus voltage. Based on equation (19) we are able to design Error! Reference source not found. as the output variables. Error! Reference source not found. is control input variable and others belong to bus voltage DC component control loop of the disturbance term. Based on equation (20), we are able to design Error! Reference source not found. as control output variable. Error: Reference source not found. is control loop controlling input variables with value at 0 and it removes bus voltage fluctuation.

Linearize the above equation, we can reach:

$$
\left\{\begin{array}{c}
\mathrm{U}_{\mathrm{sc}}^{(\mathrm{ss})} \mathrm{I}_{\mathrm{sco}}^{(\mathrm{ss})}+\mathrm{p}_{\mathrm{b}}^{(\mathrm{ss})}-\mathrm{p}_{\mathrm{o}}^{(\mathrm{ss})}-\frac{\mathrm{U}_{\mathrm{o}}^{(\mathrm{ss})}}{\mathrm{R}_{\mathrm{L}}}=0 \\
\tilde{\mathrm{u}}_{\mathrm{o}}(\mathrm{s})=\frac{\mathrm{sL}_{\mathrm{sc}} \mathrm{I}_{\mathrm{sco}}^{(\mathrm{ss})}+\mathrm{U}_{\mathrm{sc}}^{(\mathrm{ss})}}{\frac{1}{2} \mathrm{sC}+\frac{1}{\mathrm{R}_{\mathrm{L}}}} \tilde{\mathrm{i}}_{\mathrm{sco}}(\mathrm{s})+\frac{\frac{1}{2} \mathrm{sL}_{\mathrm{sc}} \mathrm{I}_{\mathrm{sct}}^{(\mathrm{ss})}}{\frac{1}{2} \mathrm{sC}+\frac{1}{\mathrm{R}_{\mathrm{L}}}} \tilde{\mathrm{I}}_{\mathrm{sct}}(\mathrm{s})+\frac{\frac{1}{2} \mathrm{sL}_{\mathrm{sc}} \mathrm{I}_{\mathrm{scs}}^{(\mathrm{ss})}}{\frac{1}{2} \mathrm{sC}+\frac{1}{\mathrm{R}_{\mathrm{L}}}} \tilde{\mathrm{I}}_{\mathrm{scs}}(\mathrm{s})+\frac{\tilde{\mathrm{p}}_{\mathrm{b}}(\mathrm{s})-\tilde{\mathrm{p}}_{\mathrm{o}}(\mathrm{s})}{\frac{1}{2} \mathrm{sC}+\frac{1}{\mathrm{R}_{\mathrm{L}}}}
\end{array}\right.
$$




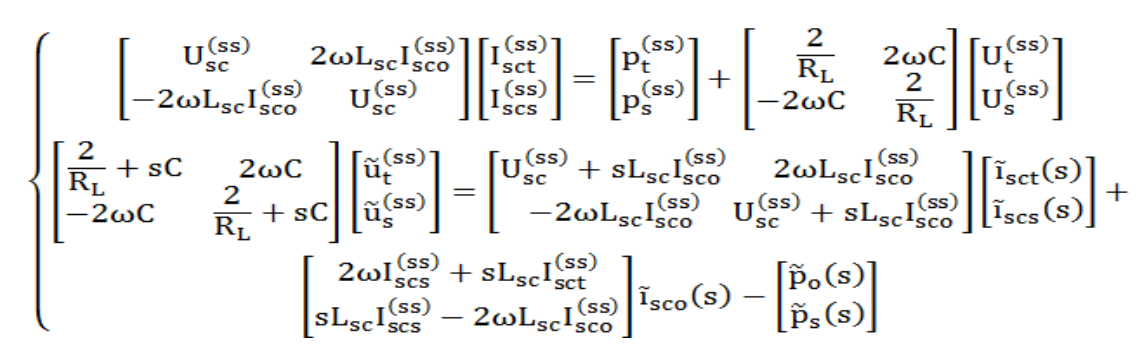

Based on the above equation, we are able to design supercapacitor voltage outer loop control strategy as follows:

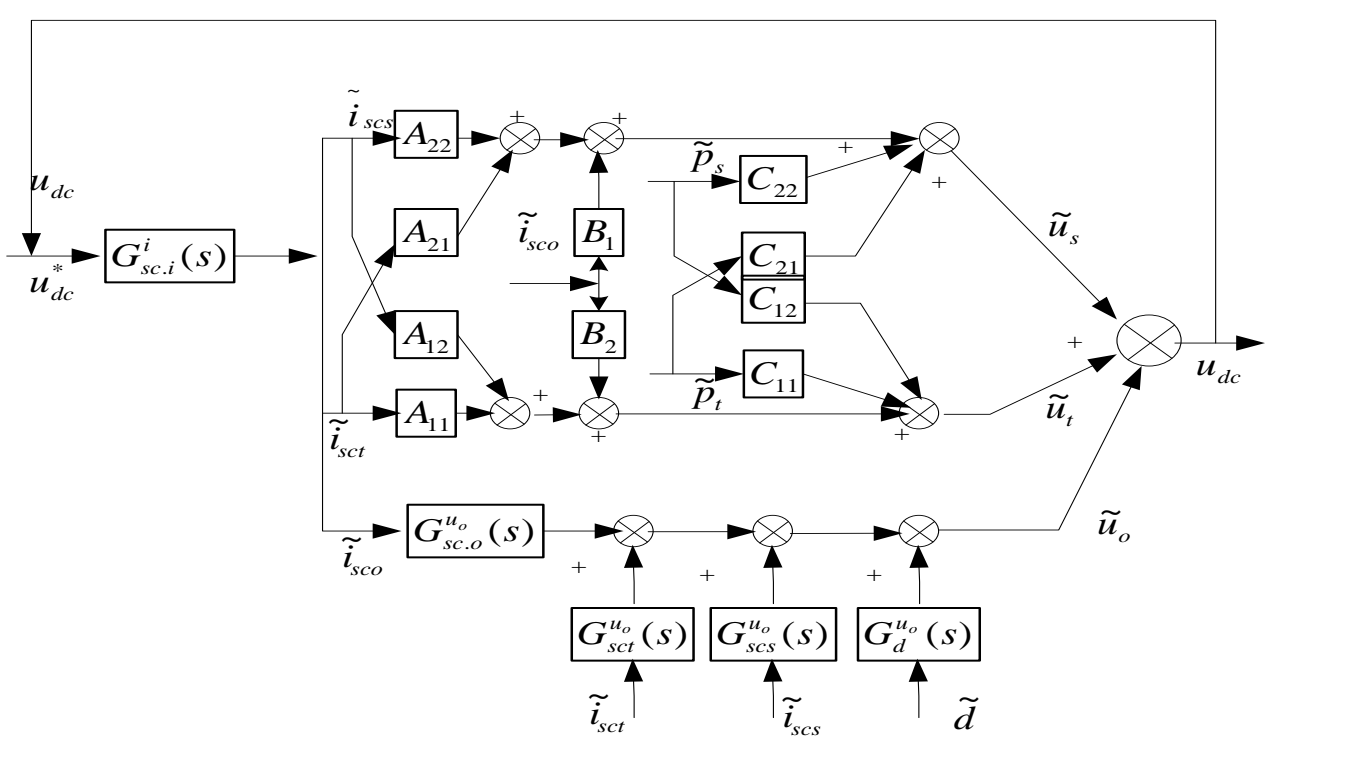

Figure 5. Supercapacitor Voltage Outer Loop Control

In the figure:

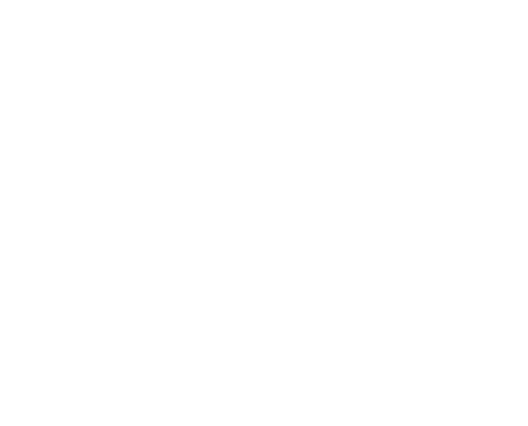

$$
\begin{gathered}
\mathrm{G}_{\mathrm{sc.o}}^{\mathrm{u}_{\mathrm{o}}}(\mathrm{s})=\frac{\mathrm{sL}_{\mathrm{sc}} \mathrm{I}_{\mathrm{sco}}^{(\mathrm{ss})}+\mathrm{U}_{\mathrm{sc}}^{(\mathrm{ss})}}{\frac{1}{2} \mathrm{sC}+\frac{1}{\mathrm{R}_{\mathrm{L}}}} \\
\mathrm{G}_{\mathrm{sc.t}}^{\mathrm{u}_{\mathrm{o}}}(\mathrm{s})=\frac{\frac{1}{2} \mathrm{sL}_{\mathrm{sc}} \mathrm{I}_{\mathrm{sct}}^{(\mathrm{ss})}}{\frac{1}{2} \mathrm{sC}+\frac{1}{\mathrm{R}_{\mathrm{L}}}} \\
\mathrm{G}_{\mathrm{sc.s}}^{\mathrm{u}_{\mathrm{o}}}(\mathrm{s})=\frac{\frac{1}{2} \mathrm{sL}_{\mathrm{sc}} \mathrm{I}_{\mathrm{scs}}^{(\mathrm{ss})}}{\frac{1}{2} \mathrm{sC}+\frac{1}{\mathrm{R}_{\mathrm{L}}}} \\
\mathrm{G}_{\mathrm{d}}^{\mathrm{u}_{\mathrm{o}}}(\mathrm{s})=\frac{1}{\frac{1}{2} \mathrm{sC}+\frac{1}{\mathrm{R}_{\mathrm{L}}}}
\end{gathered}
$$

$G_{s c . i}^{i}(s)$ is supercapacitor current closed-loop transfer function.

\section{Simulation and Test Result}


In order to certify the accuracy of aforesaid control strategy, it is hereby establish PSCAD simulation model.

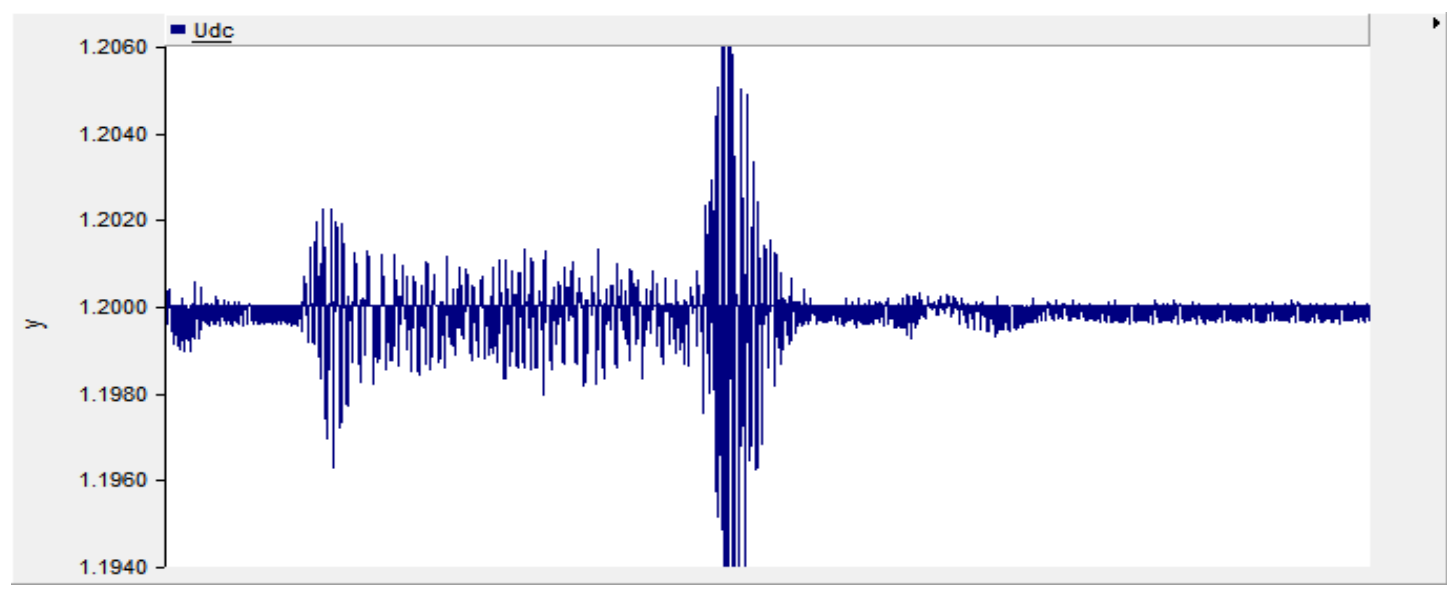

Figure 6. DC Bus Voltage Waveform Not Using Power Frontfeed

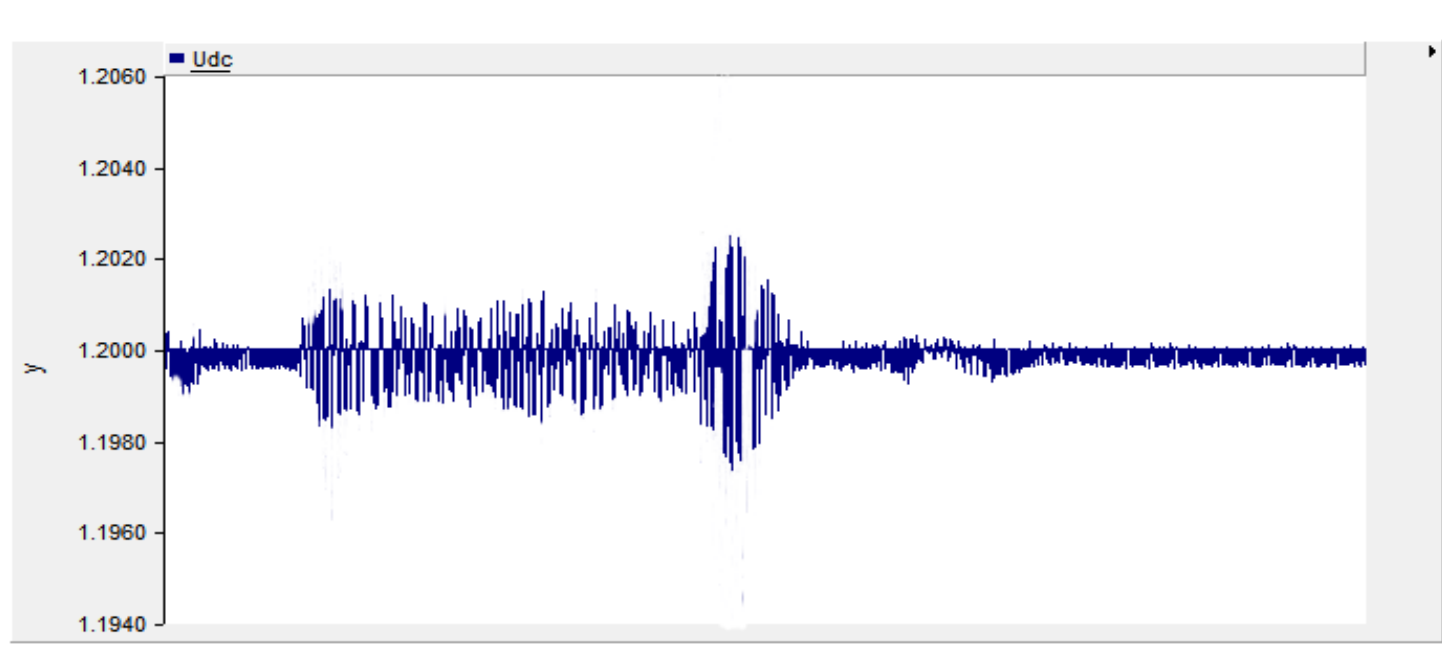

Figure 7. DC Bus Voltage Waveform Using Power Frontfeed

As what are illustrated jn Figure 6 and Figure 7, DC bus voltage has large oscillation amplitude not using power frontfeed and the use of power front feed has obviously improved voltage oschlation. It indicates that the strategy is much effective in stabilizing DC bus voltage.

Based on Figure 8, we can see that output power of storage battery using hysteresis control is o in a certain period, namely, it stops working to have effectively reduced charging/discharging times. Based on Figure 9, we can see that full power in this part is undertaken by the supercapacitor.

Based on the simulation results, we are able to use the control strategy on hybrid energy storage DC end proposed in this paper to further stabilize DC bus linear voltage so as to effectively reduce storage battery charging/discharging times, to extend its service life and to further exhibit the advantage of hybrid energy storage. 


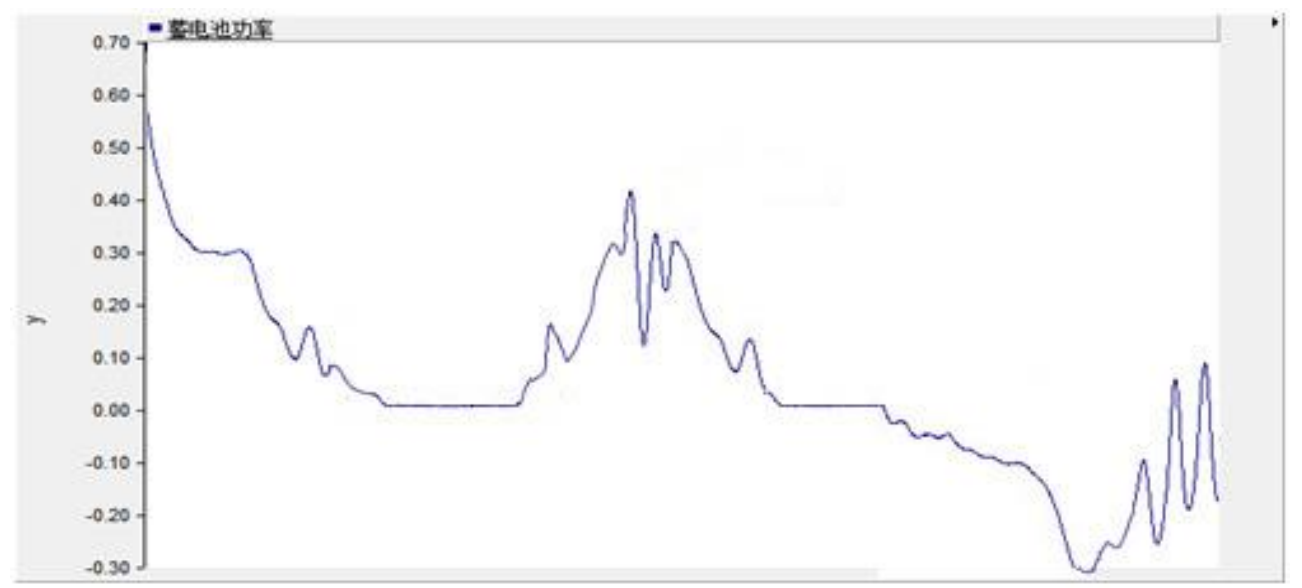

Figure 8. Storage Battery Power Using Hysteresis Control



Figure 9. Storage Battery Power Not Using Hysteresis Control

\section{Conclusion}

Energy storage is the key element for stable and reliable operation in micro grid. As to hybrid ene gy storage control, it puts forward double closed-loop control with power frontfeed to solve stability of DC bus voltage and it is able to avoid bus voltage fluctuation caused by power control lag as the result of untimely feedback. As to energy storage components, (n order to reduce some unnecessary power discharging of storage battery, it adds hysteresis comparator to effectively extend service life of storage battery. Simulation tests just verify the plausibility of the aforesaid strategy and it is able to further exhibit the advantage of hybrid energy storage.

\section{Acknowledgments}

The project is sponsored by Shenyang Bureau of Science and Technology with project number at: F14-231-1-21.

\section{References}

[1] D. Chen, J. Zhang, Z. Qian, “An Improved Repetitive Control Scheme for Grid-Connected Inverter With Frequency-Adaptive Capability”, IEEE Transactions on Industrial Electronics, vol. 60, no. 2, (2013), pp. 814-823.

[2] R. Zamora and A. K. Srivastava, "Controls for microgrids with storage: Review, challenges, and research needs", Renewable and Sustainable Energy Reviews, vol. 14, no. 7, (2010), pp. 2009-2018.

[3] J. Sun, "Impedance-Based Stability Criterion for Grid-Connected Inverters", IEEE Transactions on power electronics, vol. 26, no. 11, (2011), pp. 30753078. 
[4] W. Zhang and Qiu Ming, "Application of energy storage technologies in power grids”, Power System Technology, (in Chinese), vol. 33, no. 7, (2009), pp. 1-9.

[5] N. Mendis, "Management of battery-supercapacitor bybrid energy storage and synchronous condenser for isolated operation of PMSG based variable-speed wind turbine generating systems", IEEE Transactions on Smart Grid, vol. 5, no. 2, (2014), pp. 944-953.

[6] H. Zhou, "Composite energy storage system involving battery and ultracapacitor with dynamic energy management in microgrid applications", IEEE Transactions on Power Electronics, vol. 26, no. 3, (2011), pp. 923-930.

[7] C. Wang, "Dispatch strategies of PV-battery microgrid in different scenarios", Power System Technology, (in Chinese), vol. 37, no. 7, (2013), pp. 1776-1782.

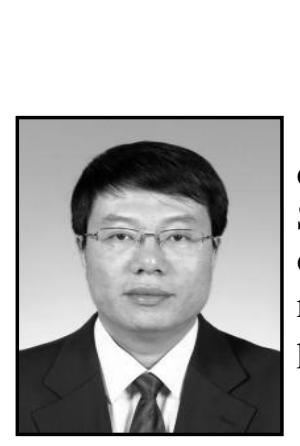

\section{Authors}

Tieyan Zhang was born in 1962. He received the $\mathrm{Ph}$. D. degree in control theory and control engineering from Northeastern University, Shenyang, China, in 2007. He is currently a professor and president of Shenyang University of Technology, Liaoning. His current research interests include fuzzy controls, fault diagno $1 \mathrm{~s}$ on electric power systems, and stability analysis on smart grids

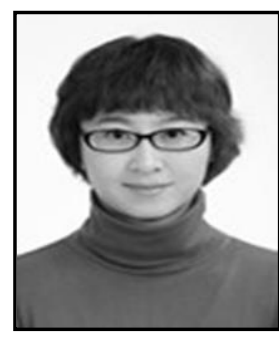

Di Bai, was born 1979. She received the M.S degree in Electrical Engineering from Shenyang University of Technology. She is an associate Professor of Shenyang Institue of Engineering. Her current research interests include distribution system analysis, distribution network crash recovery, etc.

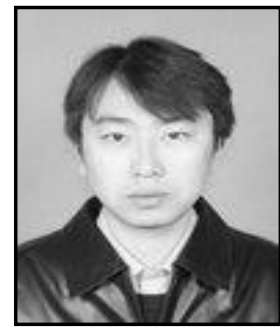

Zheng Yang, was born 1978. He received the M.S degree in Software \& Theory from Northeastern University. He is an associate Professor of Shenyang Institute of Engineering. His current research interests include oomputer research and calculation.

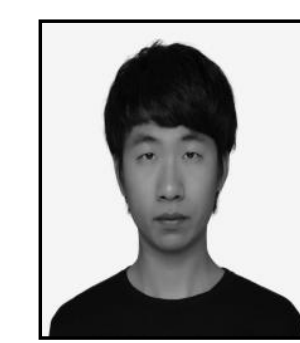

Zhibin Long was born in 1992. He received the B. E. degree in Electrical Engineering from Shenyang Institute of Engineering, Shenyang, China in 2015 . He is currently working towards the M. S. degree in Electrical Engineering in The University of New South Wales, Sydney, Australia.

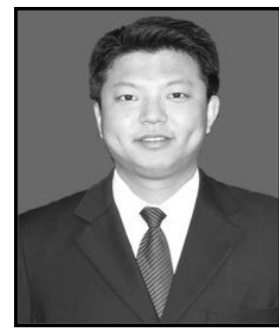

Baiyu Gao, was born in July 1978. Now he works in marketing department at state grid Liaoning power company, Shenyang, China. $\mathrm{He}$ received bachelor degree of economics at International Economics and Trade in Liaoning University and in the period he minored in law and got a bachelor's degree of law. During the work, he got professional master degree of engineering Shenyang Agriculture University. 